\title{
STUDENT AND FACULTY PERCEPTIONS OF CAPSTONE PURPOSES: WHAT CAN ENGINEERING LEARN FROM OTHER DISCIPLINES?
}

\author{
Julie Vale ${ }^{l^{*}}$, Karen Gordon ${ }^{l}$, Russell Kirkscey ${ }^{2}$, and Jennifer Hill ${ }^{3}$ \\ ${ }^{1}$ University of Guelph, ${ }^{2}$ Penn State Harrisburg, ${ }^{3}$ University of Gloucestershire \\ *jvale@uoguelph.ca
}

\begin{abstract}
Capstone Experiences (CE) are meant to integrate and culminate the student experience. The most common CE in the Canadian and American engineering curriculums is the final year design course, but other disciplines also have capstone experiences.

This paper presents initial results from a multiinstitutional, multi-national survey of faculty and student perceptions of capstone experiences. Here, we investigate three criteria (Values, Skills/competencies, Attitudes) and discuss differences and similarities among the disciplines and between engineering students and faculty.

There is good alignment between engineering faculty and students, but values such as openness and compassion are selected at (comparatively) lower rates by engineering faculty and students than by other disciplines. These findings provide an opportunity for engineering educators to reflect on the intentions of their $C E$; e.g., are these results an intentional outcome of engineering capstones, or an oversight on the part of engineering educators?
\end{abstract}

Keywords: Capstone, Design, Outcomes, Values, Skills and Competencies

\section{INTRODUCTION}

Accredited engineering programs across Canada and the United states require all students to engage in a capstone design experience. These experiential learning opportunities allow students to engage in a realistic engineering design process. Due to their culminating nature, capstone design courses provide a rich source of data for graduate attributes for which data is often sparse and/or low quality (e.g., ethics, lifelong learning, etc.).

Other disciplines also provide capstone experiences for their students. Some capstones (e.g., engineering design courses) focus on the skills and knowledge gained during the program, while others (e.g., [1]) are concerned primarily with the individual's personal growth and career plans. Additionally, some capstones seek to integrate multiple disciplines (e.g., [2]), while others are discipline focused, such as an individual fourth year thesis (e.g., [3]).

In all cases, capstone experiences are meant to provide a culminating and transitional experience ([4] and [5]). A wealth of research in the US (e.g., [6], [7]) has explored the intent behind these experiences. However, while crossdisciplinary research on CE exists (e.g., [8] integrated results from the first four years of the Senior Year Experience National Conference), [9] observes that "there is a need for additional multi-discipline, multi-institutional studies to more fully explore the variation of capstones..." (see also [10]). In addition, there is little exploration of the alignment between how students and faculty view the intent and result of these experiences [11].

In this paper, we focus on three broad Learning Outcome categories, which were defined for participants as follows:

Values: your principles or standards of behavior; your judgment of what is important in life.

Skills/Competencies: the broad range of abilities necessary to perform well in university, employment or society, with results of acceptable quality.

Attitudes: your way of thinking or feeling about someone or something, typically one that is reflected in [your] behavior.

\subsection{Background}

Existing research has explored methods of describing the overarching goals of a capstone experience, including the use of surveys ([11], [12]) document analyses [9], and expert panels [13] to describe programmatic objectives and goals, but none of these studies investigate whether these outcomes are affected (or perceived to be affected) in students who actually take a capstone course.

The Canadian and American engineering $\mathrm{CE}$ is required for accreditation and must include a culminating design experience [14], [15]. In [16], the authors surveyed 25 engineering capstone courses across Canada and found that all involved delivery through a group project, which was then assessed via a written report, an oral presentation, and in some cases a working prototype. In most cases, the projects were found to be open-ended, and the problems had been generated from either the faculty advisor's research program, an industry partner, or in some cases the problem had been student generated. As a result, the study 
noted that the design projects were of "diminished scope", in most cases lacking the initial stages of needs analysis and problem definition. Implicitly, this means that the students in those courses do not have the opportunity to develop related skills, values, or attitudes.

Finally, Henscheid et al. [6] investigated syllabi from over 500 public and private U.S. institutions and found that nearly three-quarters were influenced by disciplinary conventions and/departmental policies. This influence may extend to student and faculty perceptions of purposes of capstone.

\subsection{Research goals}

This paper is part of a larger research project that seeks to investigate student and faculty perceptions of the purposes of capstone experiences, including comparisons across discipline, country, and institution. In this paper, we narrow our focus to the differences between engineering and other disciplines and between engineering faculty and engineering students with the dual goals of better understanding the impact of engineering capstones on students and encouraging critical reflection on the desired outcomes of engineering capstone design courses.

\section{METHODS AND MATERIALS}

All data presented in this paper was obtained via two REB approved surveys (faculty and student) run over two years. Ethics approval was obtained at all participating institutions.

\subsection{Survey}

The survey was developed during year one of the Elon Center for Engaged Learning's Capstone Experiences Seminar [17]. At the seminar, there were 25 attendees from four countries, comprising a broad cross-section of disciplinary backgrounds. All participants had experience with teaching capstone and many participants had deep experience with pedagogical research and survey design.

The researchers leveraged the participants' expertise to develop the three categories and the item lists. A literature review (e.g., see [13] and the references therein) was also conducted to generate initial lists, which were then simplified through a process of identifying synonyms and/or identifying items of particular interest to some disciplines (e.g., an engineering participant insisted on including Professionalism, while a theology participant insisted on including Spiritual).

\subsection{Participants}

Participants were drawn from four universities in three different countries (Table 2). Individuals were invited to participate using an anonymous link distributed via email, either through list-serves or through course-based announcements. Faculty participants were excluded if they had never taught a capstone and student participants were excluded if they had never taken a capstone.

Participants were asked to select their discipline from a pre-defined list. During analysis, these disciplines were categorized (Table 1):

Engineering: Engineering STEM, Non-engineering: Physical Science, Mathematics, Medicine, Technology, Environmental Studies

Social Science: Psychology, Education, Geography, Social Science, Economics, Political Science

Humanities: Languages, Arts, History, Literature, Philosophy

Table 1: Participant numbers by discipline

\begin{tabular}{|l|l|c|c|}
\hline \multicolumn{2}{|c|}{ Discipline } & $\begin{array}{c}\text { Faculty } \\
(\mathbf{n}=67)\end{array}$ & $\begin{array}{c}\text { Student } \\
(\mathbf{n}=124)\end{array}$ \\
\hline \multirow{2}{*}{ STEM } & Non-Engineering & 9 & 50 \\
\cline { 2 - 4 } & Engineering & 10 & 17 \\
\hline \multicolumn{2}{|c|}{ Social Science } & 25 & 32 \\
\hline \multicolumn{2}{|c|}{ Humanities } & 23 & 25 \\
\hline
\end{tabular}

\section{RESULTS}

Here, we present two sets of results: (1) Participant ranking of the importance of the three categories and (2) Participant selection of items from each category that are affected by their capstone. To better represent differences and similarities among the disciplines, all results have been normalized to the number of respondents in each discipline.

Table 2: Participating institutional details

\begin{tabular}{|l|c|l|l|l|}
\hline Institution & $\begin{array}{l}\text { Approx. UG } \\
\text { population }\end{array}$ & Type & Public/Private & Country \\
\hline University of Guelph (UG) & 25,000 & Comprehensive research & Public & Canada \\
\hline Boston College (BC) & 9,000 & Liberal arts & Private & USA \\
\hline University of West England - Bristol (UWE) & 22,000 & Comprehensive teaching & Public & UK \\
\hline Penn State Harrisburg (PSU) & 4,000 & Comprehensive research & Public \\
\hline
\end{tabular}




\subsection{Categories}

Participants were asked to "rank the three categories [Values, Skills and Competencies, Attitudes] from most important to least important in the context of your capstone." (Figure 1 and Figure 2). Students in all disciplines except engineering tended to select values as most important and skills/competencies as least important. Non-engineering faculty were more varied in their responses, particularly Social Science and non-engineering STEM who selected skills/competencies and values as most and least important at similar rates. These results are strikingly different for engineers, who overwhelmingly choose skills/competencies as most important. engineering students tended to select values as least important, while engineering faculty split between values and attitudes as least important.

\subsection{Item descriptors}

For each of the three categories, participants selected their top five descriptors from pre-populated lists; for example, in values, faculty participants were asked "What values do you think are affected by the capstone?" The option to select 'none' was included. Table 3 shows the collected results, with heat maps for each subsection (e.g., student values).

Notable disciplinary differences between students (Table 4) include

Values: Engineering selects Thoughtfulness, Compassion, and Openness at much lower rates (comparatively) while humanities selects Professionalism at much lower rates

Skills: Engineering selects Problem solving at a much higher rate (interestingly, all groups select Critical thinking at high rates, which begs the questions of what the perceived difference is), STEM overall selects Communication - written at higher rates, and engineering selects Communication - Verbal, Lifelong learning, and Interpersonal skills at lower rates (note that all groups select teamwork at similar rates, again raising questions of what differentiates teamwork from interpersonal skills). Finally, social science students select Research at lower rates.

Attitudes: Engineering selects Professional at higher levels and Concerned for the well being of others at lower rates. Interestingly, engineering and social sciences select Selfaware at similar (lower) rates, while humanities and non-engineering STEM select it at similar (higher) rates. Humanities selects Motivated/Enthusiastic at much lower rates.

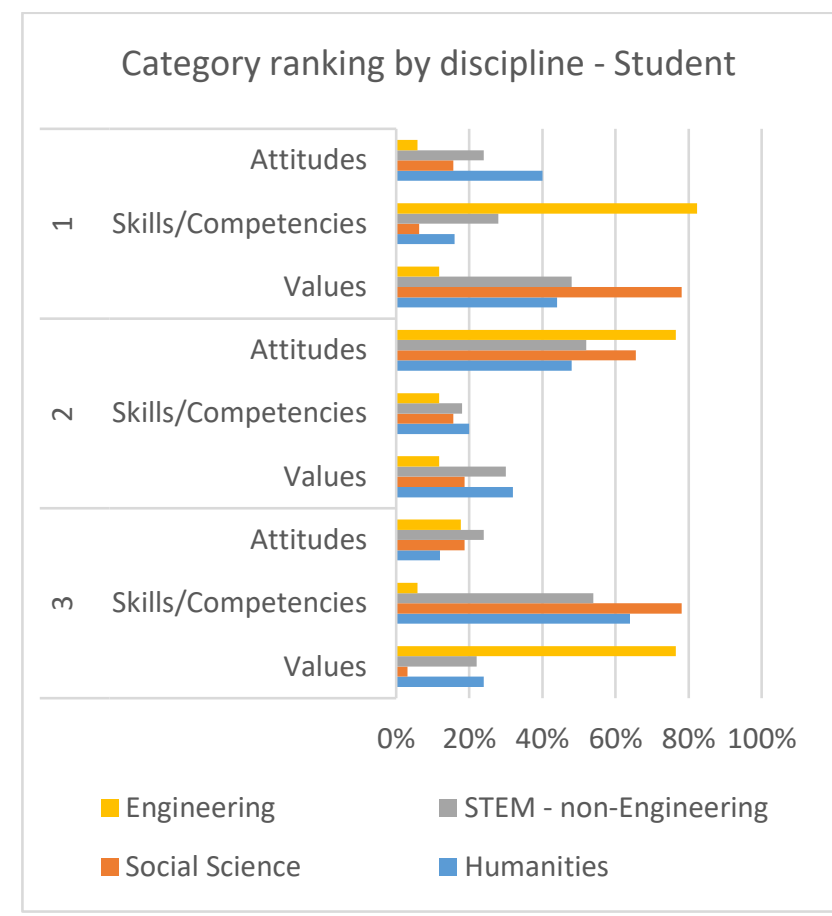

Figure 1: Student category ranking from most important (1) to least important (3). Split is shown according to discipline

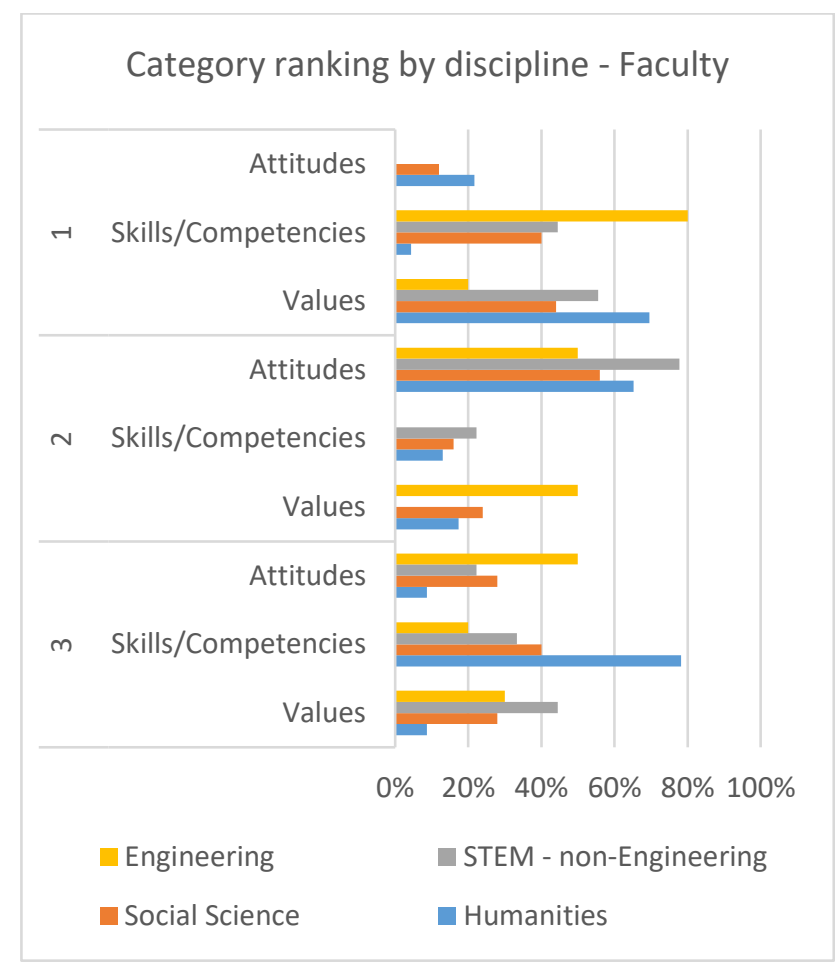

Figure 2: Faculty category ranking from most important (1) to least important (3). Split is shown according to discipline 
Table 3: Heat maps for all terms organized by category and by faculty vs student

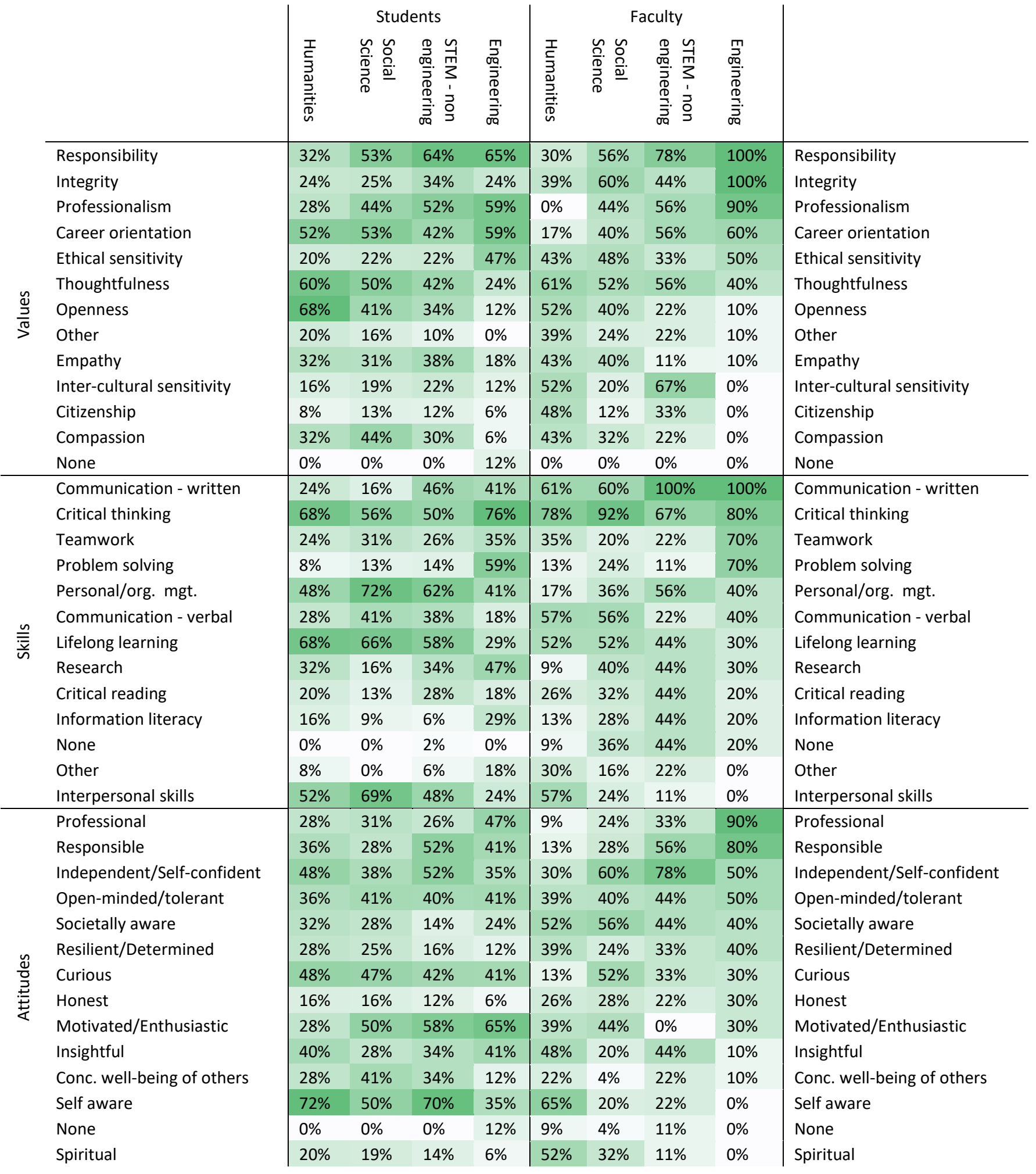


Table 4: Differences between disciplines in the student group - identified via standard deviation

\begin{tabular}{|c|c|c|c|c|c|}
\hline 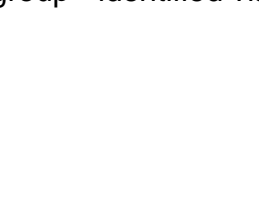 & 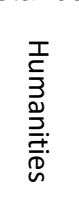 & 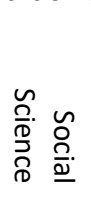 & 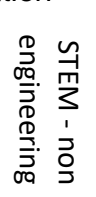 & 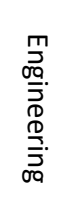 & 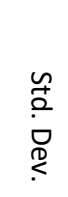 \\
\hline Problem solving & $8 \%$ & $13 \%$ & $14 \%$ & $59 \%$ & 0.24 \\
\hline $\begin{array}{l}\text { Motivated/ } \\
\text { Enthusiastic }\end{array}$ & $28 \%$ & $50 \%$ & $58 \%$ & $65 \%$ & 0.16 \\
\hline Responsibility & $32 \%$ & $53 \%$ & $64 \%$ & $65 \%$ & 0.15 \\
\hline $\begin{array}{l}\text { Communication - } \\
\text { written }\end{array}$ & $24 \%$ & $16 \%$ & $46 \%$ & $41 \%$ & 0.14 \\
\hline Professionalism & $28 \%$ & $44 \%$ & $52 \%$ & $59 \%$ & 0.13 \\
\hline Ethical sensitivity & $20 \%$ & $22 \%$ & $22 \%$ & $47 \%$ & 0.13 \\
\hline Research & $32 \%$ & $16 \%$ & $34 \%$ & $47 \%$ & 0.13 \\
\hline Thoughtfulness & $60 \%$ & $50 \%$ & $42 \%$ & $24 \%$ & 0.15 \\
\hline Compassion & $32 \%$ & $44 \%$ & $30 \%$ & $6 \%$ & 0.16 \\
\hline Self aware & $72 \%$ & $50 \%$ & $70 \%$ & $35 \%$ & 0.17 \\
\hline Lifelong learning & $68 \%$ & $66 \%$ & $58 \%$ & $29 \%$ & 0.18 \\
\hline Interpersonal skills & $52 \%$ & $69 \%$ & $48 \%$ & $24 \%$ & 0.19 \\
\hline Openness & $68 \%$ & $41 \%$ & $34 \%$ & $12 \%$ & 0.23 \\
\hline
\end{tabular}

Table 5: Differences between disciplines in the faculty group - identified via standard deviation

\begin{tabular}{|c|c|c|c|c|c|}
\hline & 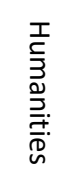 & 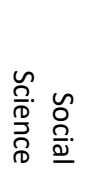 & 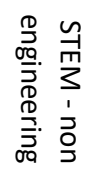 & 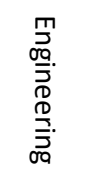 & 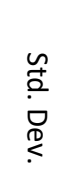 \\
\hline $\begin{array}{l}\text { Professionalism } \\
\text { (Value) }\end{array}$ & $0 \%$ & $44 \%$ & $56 \%$ & $90 \%$ & 0.37 \\
\hline $\begin{array}{l}\text { Professional } \\
\text { (Attitude) }\end{array}$ & $9 \%$ & $24 \%$ & $33 \%$ & $90 \%$ & 0.35 \\
\hline $\begin{array}{l}\text { Responsibility } \\
\text { (Value) }\end{array}$ & $30 \%$ & $56 \%$ & $78 \%$ & $100 \%$ & 0.30 \\
\hline $\begin{array}{l}\text { Responsible } \\
\text { (Attitude) }\end{array}$ & $13 \%$ & $28 \%$ & $56 \%$ & $80 \%$ & 0.30 \\
\hline Problem solving & $13 \%$ & $24 \%$ & $11 \%$ & $70 \%$ & 0.28 \\
\hline Integrity & $39 \%$ & $60 \%$ & $44 \%$ & $100 \%$ & 0.28 \\
\hline Teamwork & $35 \%$ & $20 \%$ & $22 \%$ & $70 \%$ & 0.23 \\
\hline Compassion & $43 \%$ & $32 \%$ & $22 \%$ & $0 \%$ & 0.18 \\
\hline Insightful & $48 \%$ & $20 \%$ & $44 \%$ & $10 \%$ & 0.18 \\
\hline Openness & $52 \%$ & $40 \%$ & $22 \%$ & $10 \%$ & 0.19 \\
\hline Citizenship & $48 \%$ & $12 \%$ & $33 \%$ & $0 \%$ & 0.21 \\
\hline Spiritual & $52 \%$ & $32 \%$ & $11 \%$ & $0 \%$ & 0.23 \\
\hline $\begin{array}{l}\text { Interpersonal } \\
\text { skills }\end{array}$ & $57 \%$ & $24 \%$ & $11 \%$ & $0 \%$ & 0.24 \\
\hline Self aware & $65 \%$ & $20 \%$ & $22 \%$ & $0 \%$ & 0.27 \\
\hline $\begin{array}{l}\text { Inter-cultural } \\
\text { sensitivity }\end{array}$ & $52 \%$ & $20 \%$ & $67 \%$ & $0 \%$ & 0.30 \\
\hline
\end{tabular}

Disciplinary differences among faculty were more striking than in the student group, possibly because of the smaller sample size (Table 5). Notable differences included

Values: Engineering selected Responsibility and Integrity at $100 \%$ and Professionalism with $90 \%$. No other grouping approached this consistency, and Humanities selected these less than $40 \%$ of the time. On the other side, engineering selected Openness, Empathy, Inter-cultural sensitivity, Citizenship, and Compassion less than $10 \%$ of the time (or never) as compared to the other disciplines, which selected them much more often.

Skills: Here, the differences are similar to that in the student group but more pronounced; e.g., $100 \%$ of engineering faculty selected teamwork, but none selected interpersonal skills.

Attitudes: These results are similar to student results, with some differences; in particular, most engineering faculty selected professional $(90 \%)$ and responsible $(80 \%)$. Both are much higher than other disciplines. Similarly, insightful and self aware see only $10 \%$ and $0 \%$ selection from engineers.

Notable differences between engineering faculty and engineering students included

Values: Faculty selected Integrity, Responsibility, and Professionalism at much higher rates than students. That said, Responsibility and Professionalism were two of the top three values selected by students, while Integrity had a much lower student selection rate.

Skills: Both Communication - written and Teamwork saw much higher selection rates by faculty $(100 \%$ and $80 \%$ ) respectively, while both of these items fell roughly in the middle of the selection rates for students.

Attitudes: Notable attitudes items selected more often by students than by faculty were Motivated/Enthusiastic, Insightful, and Self aware. Indeed, Motivated/Enthusiastic was the most common choice among students, but in the bottom half of faculty selections, while Insightful was selected by only one faculty member, and Self aware selected by none!

\section{DISCUSSION}

Our results raise several interesting questions:

1. Why do some disciplines select certain terms (e.g., teamwork), while other disciplines select similar meaning but different terms as more relevant to the capstone experience (e.g., interpersonal skills)?

2. While engineering faculty and students are closely aligned in many of their choices, what are the 
implications for the items where they are not aligned?

3. Should engineering capstones consider broadening learning outcomes to include skills, values, and attitudes that other disciplines emphasize?

In this section, we will explore these three questions. In some cases, we provide answers, but in others (particularly in 3) we pose challenges to the broader engineering teaching community.

\subsection{Apparent similarities that aren't}

Why do engineering faculty rate teamwork highly, but ignore interpersonal skills (Figure 3)? Why do other disciplines rate critical thinking highly, but ignore problem solving (Figure 4)? Why do engineering faculty select professionalism, responsibility, and integrity as their top three choices, but students only rank professionalism and responsibility in the top three, while integrity is fifth (after career orientation and ethical sensitivity and tied with thoughtfulness)? In a linguistic sense, these pairs/triples are tightly related, and yet participants clearly view them to be somewhat distinct. These issues are likely semantic and could stem from two interrelated ideas from the psychology literature.

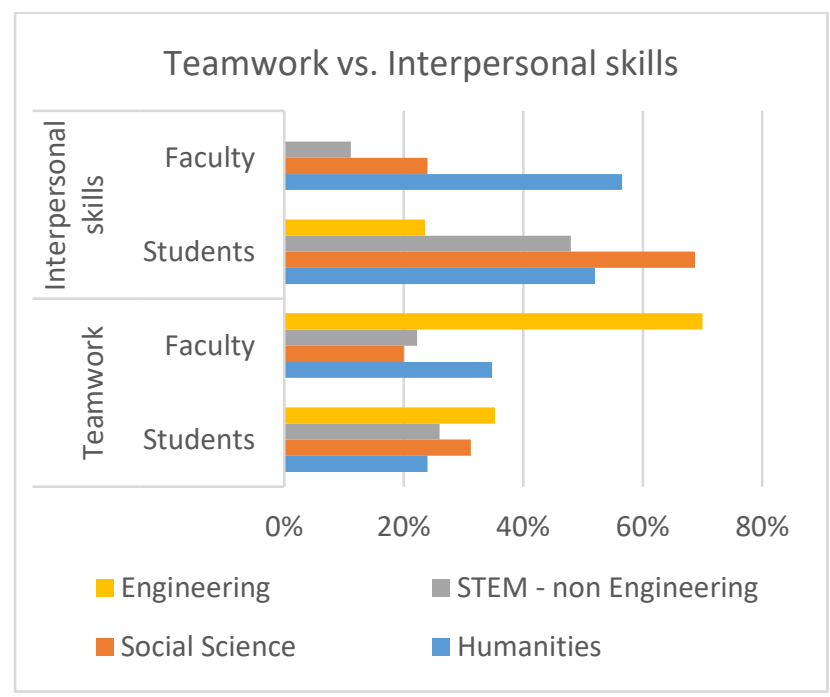

Figure 3: Disciplinary differences in the selection of the terms teamwork and interpersonal skills

In broad terms, occupational psychosis [18] means that we interpret life through our jobs. For example, if you say that doing your taxes gives you anxiety, a physician may offer a pill or other medical intervention, but if you say that to a professor, s/he may recommend a book or website to learn more about taxes.

Terministic screens [19] are the manifestations of occupational psychosis and help to understand the language choices that people make according to their

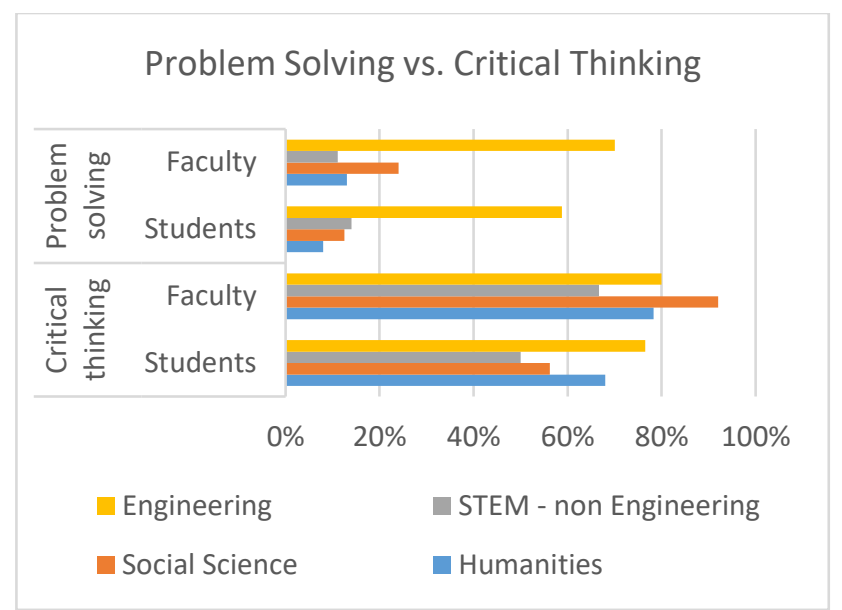

Figure 4: Disciplinary differences in the selection of the terms Problem Solving and Critical Thinking

training and profession. People in various professions have go-to metaphors that they use to create meaning in their worlds. Engineers solve problems on teams. As a result, they may use those terms to "fix" non-engineering problems. Additionally, they may not use the phrase interpersonal skills in their professional lives because it is a subset of teamwork.

The same applies to problem solving vs critical thinking. Problem solving stresses a result, while critical thinking proves students can analyze an issue (e.g., see [19]). In general, engineering underscores problem solving, while other disciplines emphasize critical thinking.

Another layer of complexity in this discussion arises due to Graduate Attributes. Engineering faculty, and through them engineering students, may be conditioned to the terms Teamwork and Problem Solving due to the accreditation process (both terms are heavily used by both CEAB and ABET).

Finally, students may view the term Integrity in the context of Academic integrity and therefore choose not to include it as being affected by their capstones, while faculty may have a broader interpretation.

\subsection{Student and faculty alignment}

Engineering faculty and students agree that professionalism, problem solving, and critical thinking are all affected by their engineering capstone, but three items have much higher selection rates among students than faculty: Self aware, Insightful, Motivated/Enthusiastic, and Communication - written (Figure 5).

We hypothesise that this increased emphasis is due to a disconnect on the faculty side between outcomes that are affected by the capstone verses those items that are assessed in the capstone - e.g., almost every engineering capstone has a large written component, so written communication is heavily assessed, but are we actually 
doing anything to affect students' abilities in this area? If we look to the student responses, who did not select written communication as one of their top skills, the implication is that we are not

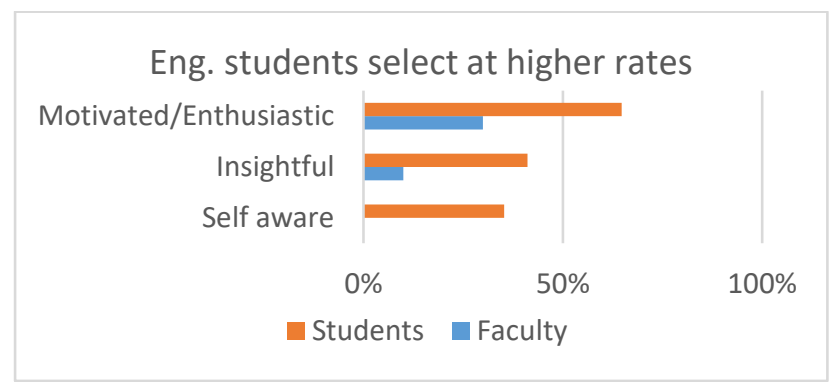

Figure 5: Items selected by engineering students at much higher rates than by engineering faculty

Finally, engineering students select the Attitude Motivated/Enthusiastic at the highest rates, while engineering faculty select it at the fourth lowest rate: our capstones are affecting student motivation and enthusiasm, even though we don't recognize that. Of course, the survey does not ask whether these items are affected in a positive or negative way - are we increasing their motivation/enthusiasm, or decreasing it? If the latter, we must seriously think about why this is occurring and how to mitigate it - further investigation is warranted.

\subsection{Disciplinary differences}

There are several disciplinary differences that cannot be explained by the semantic argument in Section 4.1. These include the overall category rankings and several items that both engineering faculty and students selected at much lower rates than other disciplines.

\subsubsection{Category ranking}

A profession is something that requires prolonged, specialized training. Perhaps this is the reason why both engineering faculty and students select skills and competencies as the most important of the three categories for capstone, while the other disciplines do not.

\subsubsection{Item rankings}

It is, perhaps, unsurprising that Engineers (both faculty and students) identify professionalism, responsibility, written communication, problem solving, and teamwork as being affected by capstones. But engineers select openness, self aware, and compassion at much lower rates than other disciplines (Figure 6). Is this an intentional outcome of engineering capstones, or an oversight on the part of engineering educators? Or is it simply a recognition that these skills and attitudes are not the primary focus of the engineering capstone?

Merriam-Webster defines 'compassion' as "sympathetic consciousness of others' distress together with a desire to alleviate it" (emphasis added). If an engineer's reason for being is to identify societal problems, and then to find (somehow optimized) solutions for those problems, then it stands to reason that compassion could be an important engineering value.

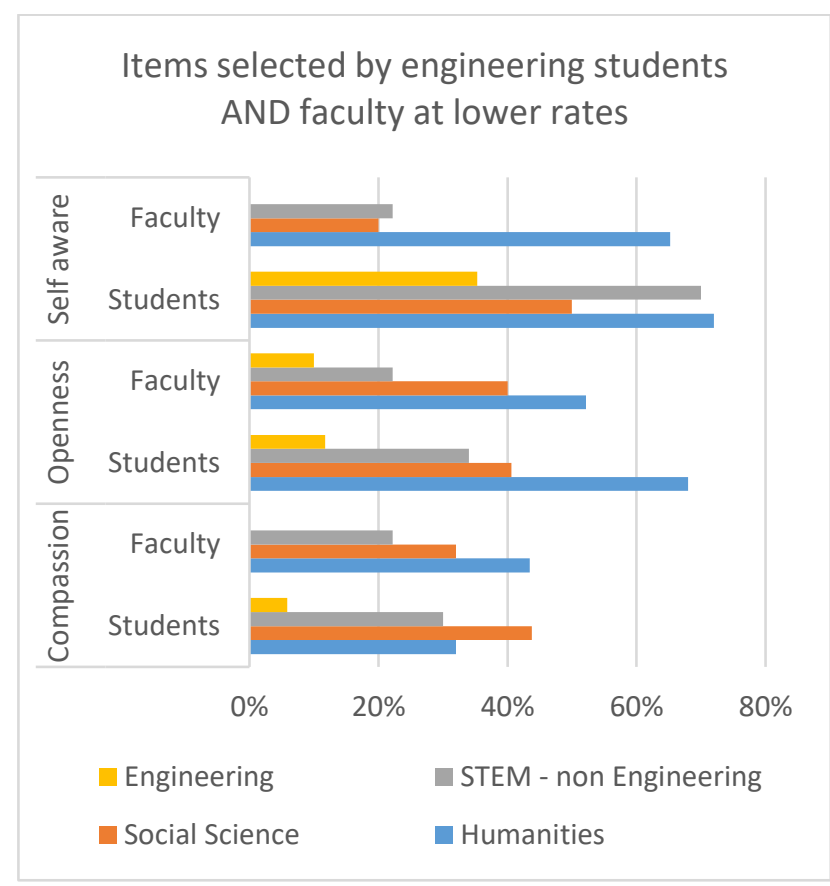

Figure 6: Items selected by both engineering students and faculty at lower rates than other disciplines

In values, which we defined as "your principles or standards of behavior; your judgment of what is important in life", the term openness ties to the dictionary definition "characterized by ready accessibility and usually generous attitude: such as [...] (2): willing to hear and consider or to accept and deal with (3): free from reserve or pretense". If compassion can be a key tool in problem identification, then it stands to reason that openness is a crucial aspect of problem definition. If engineers are closed to new ideas or are approaching problems with a preconceived solution, then they are inherently limiting the solution space.

As society at large gains a better understanding of the impact of bias on decision making and policy, it behoves engineers to reflect on the impacts of their own design choices. Indeed, if engineering faculty encourage students to select their capstone design problem with compassion and openness in mind, it may avert the common issue of fourth year design students designing and building widgets. Instead, those student engineers will be better equipped to identify real problems, and then to do the hard work of consulting with the relevant stakeholders to understand the underlying issues and the potential solutions. Only then will these students be able to make a truly significant contribution to solving society's wicked problems.

Finally, self-awareness relates to the ability to understand our own personalities and individuality. A lack 
of this trait can lead to bias, closed-mindedness, and ignorance. None of these traits is desirable in an engineer.

\subsection{Limitations}

Due to the small sample size, we were not able to perform a statistical analysis. Furthermore, participants were asked what was 'affected' - it is likely that participants will interpret this word in different ways (e.g., some may interpret it as analogous to 'assessed', while others may interpret it as analogous to 'changed'). Additionally, institutional influence on the capstone, and therefore its perceived affects, may be a confounding factor, but we were unable to investigate these institutional effects due to low sample sizes.

Future work includes additional surveys (to improve the sample size) and small group interviews.

\section{CONCLUSIONS}

While the survey results indicate that engineering students and faculty are reasonably aligned, the disciplinary differences do highlight some items deserving of reflection. In particular, we argue that engineering educators should take a step back and decide whether skills and competencies really are the most important outcome of a capstone, or whether they should instead be creating space in design courses for conversations about openness, compassion, and self-awareness. If engineering educators are truly invested in educating the whole person, then perhaps a focus on some of the 'softer' skills is in order.

\section{Acknowledgements}

The authors would like to thank the Elon Centre for Engaged Learning, which funded three of the authors to attend a three-year Capstone Seminar. This research began at the seminars and would not have been possible without Elon's generous support.

\section{References}

[1] Capstone, Morrissey College of Arts and Sciences: Boston College. Accessed on Dec. 6, 2019. [Online] https://www.bc.edu/bcweb/schools/mcas/sites/capstone.html

[2] L. Hutter, et al. "Fostering meaningful collaboration in an interdisciplinary capstone course", Proc. 49th ACM Tech. Symp. on Computer Sci. Edu., 2018.

[3] J.E. Dowd, et al. "Student learning dispositions: Multidimensional profiles highlight important differences among undergraduate STEM honors thesis writers." CBE-Life Sci. Edu., 18(2), 2019.

[4] J. Kinzie, "Taking stock of capstones and integrative learning", Peer Review, 15(4), 2013.

[5] A. Rash and K. Weld, "The Capstone Course: Origins, Goals, Methods, and Issues", PRIMUS, 23:4, 291-296, 2013.
[6] J.M. Henscheid, et al., Professing the disciplines: An analysis of senior seminars and capstone courses. Columbia, SC: Nat. Resource Ctr. for the 1st-Yr Experience and Students in Transition (NRC 1stYr EST), 2000.

[7] D.G. Young et al. 2016 national survey of senior capstone experiences: Expanding our understanding of culminating experiences. Columbia, SC: NRC 1stYr EST , 2017.

[8] J.B. Cuseo, "Objectives and benefits of senior year programs" in The senior year experience: Facilitating integration, reflection, closure, and transition $\mathrm{J} . \mathrm{N}$. Gardner \& G. B. Van der Veer, Eds., Jossey-Bass Publishers, (1998), pp. 21-36

[9] R.C. Hauhart and J.E. Grahe, Designing and teaching undergraduate capstone courses. San Francisco, CA: Jossey-Bass, 2015.

[10] R.D. Padgett and C.A. Kilgo, 2011 national survey of senior capstone experiences: Institutional-level data on the culminating experience. Columbia, SC: NRC 1stYr EST , 2012.

[11]N. Lee and D. Loton, "Capstone Purposes Across Disciplines" Studies in Higher Education, vol. 44, 2019.

[12] Schermer, T., \& Gray, S. The senior capstone: Transformative experiences in the liberal arts The Teagle Foundation, 2012.

[13] Value Rubric Development Project. (2014). Association of American Colleges and Universities. https://www.aacu.org/value/rubrics

[14] Criterion 3.4.4.4, CEAB Accreditation requirements. Accessed on Feb 15, 2020. [Online] https://engineerscanada.ca/sites/default/files/accredita tion/Accreditation-Criteria-Procedures-2019.pdf

[15] General criterion 5b ABET Accreditation requirements Accessed on Feb 15, 2020. [Online] https://www.abet.org/accreditation/accreditationcriteria/criteria-for-accrediting-engineeringprograms-2016-2017/

[16] C. Vincent and P. Wild, "Current Practices in Final Year Engineering Design Courses" Proceedings of CDEN/C2E2 Conference: Winnipeg, Manitoba, 2007.

[17]Elon Center for engaged Learning Capstone Experiences Research Seminar https://www.centerforengagedlearning.org/celseminars/ce/

[18] Burke, Kenneth, Language as Symbolic Action: Essays on Life, Literature and Method. Berkeley, CA: University of California Press, 1966.

[19] Burke, Kenneth, Permanence and Change. Los Altos, CA: Hermes Publications, 1954.

[20] Rollins.edu "Critical Thinking versus Problem Solving: A Quick Guide" Accessed on Feb 13, 2020. [Online] https://www.rollins.edu/studentaffairs/images-docs/critical-thinking-vs-problemsolving.pdf 